\title{
Use of benzo analogs to enhance antimycotic activity of kresoxim methyl for control of aflatoxigenic fungal pathogens
}

\author{
Jong H. Kim*, Noreen Mahoney, Kathleen L. Chan, Bruce C. Campbell, Ronald P. Haff and \\ Larry H. Stanker
}

Foodborne Toxin Detection and Prevention Research Unit, Western Regional Research Center, USDA-ARS, Albany, CA, USA

Edited by:

Mehdi Razzaghi-Abyaneh, Pasteur Institute of Iran, Iran

Reviewed by:

Masoomeh Shams-Ghahfarokhi,

Tarbiat Modares University, Iran

Eva-Guadalupe Lizárraga-Paulín,

Universidad Nacional Autónoma De

México, Mexico

\section{${ }^{*}$ Correspondence:}

Jong H. Kim, Foodborne Toxin

Detection and Prevention Research

Unit, Western Regional Research

Center, USDA-ARS, 800 Buchanan

Street, Albany, CA 94710, USA

e-mail: jongheon.kim@ars.usda.gov
The aim of this study was to examine two benzo analogs, octylgallate (OG) and veratraldehyde (VT), as antifungal agents against strains of Aspergillus parasiticus and A.flavus (toxigenic or atoxigenic). Both toxigenic and atoxigenic strains used were capable of producing kojic acid, another cellular secondary product. A. fumigatus was used as a genetic model for this study. When applied independently, OG exhibits considerably higher antifungal activity compared to VT. The minimum inhibitory concentrations (MICs) of OG were $0.3-0.5 \mathrm{mM}$, while that of $V T$ were $3.0-5.0 \mathrm{mM}$ in agar plate-bioassays. OG or VT in concert with the fungicide kresoxim methyl (Kre-Me; strobilurin) greatly enhanced sensitivity of Aspergillus strains to Kre-Me. The combination with OG also overcame the tolerance of $A$. fumigatus mitogen-activated protein kinase (MAPK) mutants to Kre-Me. The degree of compound interaction resulting from chemosensitization of the fungi by OG was determined using checkerboard bioassays, where synergistic activity greatly lowered MICs or minimum fungicidal concentrations. However, the control chemosensitizer benzohydroxamic acid, an alternative oxidase inhibitor conventionally applied in concert with strobilurin, did not achieve synergism. The level of antifungal or chemosensitizing activity was also "compound-strain" specific, indicating differential susceptibility of tested strains to OG or VT, and/or heat stress. Besides targeting the antioxidant system, OG also negatively affected the cell wall-integrity pathway, as determined by the inhibition of Saccharomyces cerevisiae cell wall-integrity MAPK pathway mutants. We concluded that certain benzo analogs effectively inhibit fungal growth. They possess chemosensitizing capability to increase efficacy of Kre-Me and thus, could reduce effective dosages of strobilurins and alleviate negative side effects associated with current antifungal practices. OG also exhibits moderate antiaflatoxigenic activity.

Keywords: aflatoxin, antioxidant system, Aspergillus, cell wall integrity, chemosensitization, octylgallate, strobilurin, veratraldehyde

\section{INTRODUCTION}

Controlling fungi that produce hepato-carcinogenic aflatoxins in crops, such as tree nuts, corn, peanuts, etc., is problematic as effective commercial fungicides for treating aflatoxigenic fungi are very limited (Roze et al., 2013). Aflatoxins are secondary metabolites produced mainly by the filamentous fungi Aspergillus flavus and $A$. parasiticus. Significant amounts of harvested crop can be made unsuitable for sale and consumption as a result of aflatoxin contamination. Very low level (parts per billion) of aflatoxin contamination can have a perniciously negative effect on food safety and economic value of a number of crops from year to year (Campbell et al., 2003). Therefore, effective methods are continually needed for control of aflatoxigenic fungal pathogens.

Strobilurins are widely used agricultural fungicides. Strobilurins were initially identified in the fungus Strobilurus tenacellus, and were synthetically developed into several subgroups, such as kresoxim methyl (Kre-Me), azoxystrobin, pyraclostrobin, etc. (Bartlett et al., 2002 and references therein).
The molecular target for strobilurins is the $b c_{1}$ complex (complex III; ubiquinol-cytochrome $c$ oxidoreductase, EC 1.10.2.2) in the mitochondrial respiratory chain (MRC). Strobilurins specifically bind to the $\mathrm{QP}_{\mathrm{P}}\left(\mathrm{Q}_{\mathrm{O}}\right)$ center of cytochrome $b$ (Bartlett et al., 2002 and references therein), resulting in the inhibition of MRC.

Development of fungal resistance to conventional antifungal agents is a global agricultural issue (Ghannoum and Rice, 1999; Wood and Hollomon, 2003; Possiede et al., 2009; Cools and Hammond-Kosack, 2013). For example, agricultural fields receiving continuous applications of the fungicide, strobilurin, resulted in the development of insensitivity of fungi to this fungicide (Keinath, 2009). Noteworthy is that if strobilurincontaining fungicides are applied at suboptimal time-points of fungal growth, these fungicides can actually potentiate mycotoxin production in fungi (Ellner, 2005).

Similar type of fungicide-potentiation of mycotoxin production was documented in Penicillium verrucosum, a filamentous fungal pathogen producing the mycotoxin, citrinin 
(Schmidt-Heydt et al., 2013). When P. verrucosum was treated with the fungicide "Rovral" (Iprodione), an inhibitor of DNA/RNA biosynthesis and cell division, the growth of fungi was decreased. However, a concomitant strong induction of citrinin biosynthesis also occurred in fungi with the same treatment (Schmidt-Heydt et al., 2013). Altogether, studies indicated that certain conventional fungicides could stimulate secondary metabolism, especially mycotoxin production, in fungal pathogens. Therefore, effective strategies are urgently needed to overcome counterproductive repercussions of fungicides currently in use.

Recent studies have shown that safe, natural phenolic compounds or their structural derivatives (e.g., benzo derivatives) could act as potent antifungal or antimycotoxigenic agents (Beekrum et al., 2003). For example, vanillic or caffeic acid not only inhibited the growth of Fusarium verticillioides, but also reduced its production of the mycotoxin, fumonisin (Beekrum et al., 2003). Natural benzo derivatives could also effectively inhibit the growth of A. fumigatus, A. flavus, A. terreus, and Penicillium expansum (Kim et al., 2011). These fungi are causative agents of human invasive aspergillosis or are producers of mycotoxins, including aflatoxin, patulin, gliotoxin, etc. The redoxactive natural phenolic agents can be potent redox cyclers that inhibit fungal growth by disrupting cellular redox homeostasis (and thus triggering cellular oxidative stress) (Guillen and Evans, 1994; Jacob, 2006). For defense, the fungal antioxidant system, such as oxidative signaling pathway, plays an important role for fungal tolerance to those phenolic agents (Kim et al., 2011).

Genes involved in stress-signaling pathways are also important for fungal virulence, pathogenesis and protection from oxidative burst exerted by the host (Washburn et al., 1987; Hamilton and Holdom, 1999; Clemons et al., 2002; de Dios et al., 2010). Oxidative stress signals sensed by a fungal cell are incorporated into the upstream mitogen-activated protein kinase (MAPK) pathway, which regulates the expression of the downstream response genes (such as antioxidant enzyme genes) detoxifying the stress (Miskei et al., 2009). In A. fumigatus, SakA and $\mathrm{MpkC}$ are orthologous MAPKs to Saccharomyces cerevisiae Hoglp, which plays a key role in countering oxidative stress (Toone and Jones, 1998; Lee et al., 2002; Xue et al., 2004; Reyes et al., 2006; Miskei et al., 2009).

Chemosensitization is a strategy where combined application of certain types of compounds along with a conventional fungicide/drug enhances the effectiveness of the conventional agents (Niimi et al., 2004; Agarwal et al., 2012; Campbell et al., 2012). Noteworthy is that certain benzo derivatives possessed antifungal chemosensitizing capability. In our prior study, co-application of antifungal agents with chemosensitizing benzo derivatives, such as 2-hydroxy-5-methoxybenzaldehyde, greatly enhanced the efficacy of antifungal agents (Kim et al., 2011). Thus, chemosensitization could lead to lowering dosages of conventional fungicides/drugs required for control of pathogens, especially drug-resistant strains. Collectively, these studies showed the potential for safe, natural phenolics to serve as effective antifungal and/or antimycotoxigenic agents.

In nature, in addition to oxidative stress, high temperature (heat) stress is another type of environmental challenge that many microbes face, which also triggers "signaling cascades" in fungal cells (Morano et al., 2012). Heat treatment is also a strategy to prevent contamination by food spoilage fungi in foods (Dagnas and Membré, 2013). In corn, artificial drying of maize kernels with high temperatures is one of the postharvest practices to prevent fungal growth and aflatoxin production (Hawkins et al., 2005). A prior study showed that heat treatment at $70^{\circ} \mathrm{C}$ significantly reduced the maize kernel infection of $A$. flavus. However, heat treatment had no effect on aflatoxin concentration, which reflects the heat stability of the mycotoxin (Hawkins et al., 2005). Also, heat treatment can result in deterioration of the quality of the crop (seed breakage, viability, etc.). Therefore, development of new alternative strategies, which warrant early intervention of mycotoxin production/fungal growth as well as the quality of harvested crops, is necessary.

In this study, we investigated the role of two benzo derivatives, octylgallate (OG) and veratraldehyde (VT), currently used as food additives, as antifungal agents against strains of A. flavus, A. parasiticus, or A. fumigatus. OG and VT are generally regarded as safe (GRAS) reagents (FDA, 2011). We also evaluated antifungal chemosensitizing capacities of OG and VT, especially for overcoming strobilurin resistance of Aspergillus MAPK gene deletion mutants (sakA $\Delta$, $m p k C \Delta)$. Kre-Me, containing (E)-methyl methoxyiminoacetate group in the structure, was tested as an exemplary strobilurin. Kre-Me is currently applied in the agricultural field for control of various fungal diseases caused by ascomycete, basidiomycete, oomycete, etc., while it exhibited high toxicity to the agriculturally important insects, bees (Bartlett et al., 2002). Our results showed that OG could serve as a potent antifungal chemosensitizer to Kre-Me for controlling Aspergillus strains.

\section{MATERIALS AND METHODS MICROBIAL STRAINS AND CULTURE CONDITIONS}

Microbial strains used in this study are summarized in Table 1. Aspergillus strains were cultured on potato dextrose agar (PDA) at $30^{\circ} \mathrm{C}$, except otherwise noted in the text. Yeast strains, wild type (WT) and gene deletion mutants of Saccharomyces cerevisiae (Table 1), were cultured on Synthetic Glucose (SG; Yeast nitrogen base without amino acids $0.67 \%$, glucose $2 \%$ with appropriate supplements: uracil $0.02 \mathrm{mg} \mathrm{mL}^{-1}$, amino acids $0.03 \mathrm{mg} \mathrm{mL}^{-1}$ ) or Yeast Peptone Dextrose (YPD; Bacto yeast extract 1\%, Bacto peptone $2 \%$, glucose $2 \%$ ) medium at $30^{\circ} \mathrm{C}$.

\section{CHEMICALS}

Antifungal compounds, kresoxim methyl (Kre-Me; strobilurin), octylgallate (octyl 3,4,5-trihydroxybenzoic acid; OG), veratraldehyde (3,4-dimethoxybenzaldehyde; VT), benzohydroxamic acid (BHAM) (Figure 1), were procured from Sigma Co. (St. Louis, MO, USA). Each compound was dissolved in dimethylsulfoxide (DMSO; absolute DMSO amount: $<2 \%$ in media) before incorporation into culture media (except for those plates used in aflatoxin assays; see below). Throughout this study, control plates (No treatment) contained DMSO at levels equivalent to that of cohorts receiving antifungal agents, within the same set of experiments. 
Table 1 | Microbial strains used in this study.

\section{Characteristics}

\section{Aspergillus}

A. flavus 3357

A. flavus 4212

A. flavus 21882

A. flavus 18543

A. parasiticus 5862

A. parasiticus 2999

A. fumigatus AF293

A. fumigatus sakA $\Delta$

A. fumigatus $m p k C \Delta$ toxigenic fungus
Plant pathogen (aflatoxin), Human pathogen (aspergillosis), Reference toxigenic (aflatoxin-producing) strain used for genome sequencing

Plant pathogen (aflatoxin), Human pathogen (aspergillosis)

Atoxigenic (aflatoxin non-producing) strain, A pesticide active ingredient displacing toxigenic fungus

Atoxigenic strain, A pesticide active ingredient displacing

Plant pathogen (aflatoxin)

Plant pathogen (aflatoxin)

Human pathogen (aspergillosis), Parental strain, Reference clinical strain used for genome sequencing

Human pathogen (aspergillosis), Mitogen-Activated Protein Kinase (MAPK) gene deletion mutant derived from AF293

Human pathogen (aspergillosis), MAPK gene deletion mutant derived from AF293

\section{Source/references}

NRRL ${ }^{a}$, Aspergillus Comparative Database

NRRL

NRRL, Aspergillus flavus NRRL 21882 Fact Sheet

NRRL, Ehrlich and Cotty (2004)

NRRL

NRRL

Xue et al. (2004); Aspergillus Comparative Database

Xue et al. (2004)

Reyes et al. (2006)

\section{Saccharomyces}

S. cerevisiae BY4741

Model yeast, Parental strain (Mat a

his3 $\Delta 1$ leu2 $\Delta 0$ met $15 \Delta 0$ ura3 $\Delta 0$ )

S. cerevisiae bck $1 \Delta$

MAPK kinase kinase mutant derived from BY4741

$(\mathrm{SGD})^{\mathrm{b}}$

S. cerevisiae slt2 $\Delta$

MAPK mutant derived from BY4741

SGD

SGD

a NRRL, National Center for Agricultural Utilization and Research, USDA-ARS, Peoria, IL, USA.

b Saccharomyces Genome Database. Available online: http://www.yeastgenome.org (accessed on 10 January 2014).<smiles>CCCCCOC(=O)c1cc(O)c(O)c(O)c1</smiles>

1

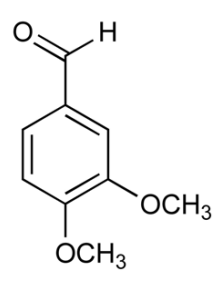

2

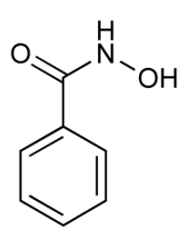

3
FIGURE 1 | Structures of benzo analogs used in this study. (1) octylgallate (OG); (2) veratraldehyde (VT); (3) benzohydroxamic acid (BHAM).

\section{SUSCEPTIBILITY TESTING}

\section{Agar plate-bioassay in Aspergillus}

In agar plate-bioassays, susceptibility of filamentous fungi to OG, VT, or Kre-Me, alone or in combination, were measured based on percent radial growth of treated compared to control fungal colonies (see Figures and Tables for test concentrations). The percent inhibition of growth was calculated using the Vincent equation (Vincent, 1947) [\% inhibition $=100(C-T) / C$; where $C=$ diameter of fungal colony on control plate (receiving only DMSO), and $T=$ diameter of fungal colony on the treated plate]. Minimum inhibitory concentration (MIC) values on agar plates were based on triplicate assays and defined as the lowest concentration of agent where no fungal growth was visible on the plate. For the above assays, fungal conidia $\left(5 \times 10^{3}\right)$ were diluted in phosphate buffered saline and applied as a drop onto the center of
PDA plates with or without antifungal compounds. Growth was observed for 5-7 days.

\section{CLSI liquid bioassay in Aspergillus}

To determine the precise level of chemosensitizing activities of OG or BHAM $(0.00625,0.0125,0.025,0.05,0.1,0.2,0.4,0.8 \mathrm{mM})$ to $\operatorname{Kre}-\mathrm{Me}\left(0.5,1,2,4,8,16,32 \mu \mathrm{g} \mathrm{mL}^{-1}\right)$ in the strains of Aspergillus, checkerboard bioassays (triplicate) $\left(0.4 \times 10^{4}-5 \times\right.$

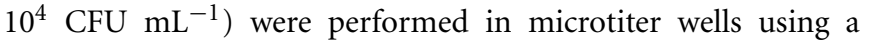
broth microdilution method (in RPMI 1640 medium; Sigma Co., St. Louis, MO, USA), according to protocols outlined by the Clinical and Laboratory Standards Institute (CLSI) M38A (CLSI, 2008). OG was chosen since this compound showed much higher antifungal activity than VT (see Results). For comparison, BHAM, an alternative oxidase (AOX) inhibitor conventionally used in combination with strobilurin, was also included as a reference chemosensitizer in this test. RPMI 1640 medium was supplemented with $0.03 \%$ L-glutamine and buffered with $0.165 \mathrm{mM} 3$-[N-morpholino] propanesulfonic acid. MICs, lowest concentration of agents showing no visible fungal growth in microtiter wells $(200 \mu \mathrm{L}$ per well), were assessed after 48 and $72 \mathrm{~h}$. Minimum fungicidal concentrations (MFCs), lowest concentration of agents showing $\geq 99.9 \%$ fungal death, were determined following completion of MIC assays by spreading entire volumes of microtiter wells $(200 \mu \mathrm{L})$ onto individual PDA plates, and culturing for another 48 and $72 \mathrm{~h}$. Compound interactions, Fractional Inhibitory Concentration Indices (FICIs) and Fractional Fungicidal Concentration Indices (FFCI), were calculated as follows: FICI or FFCI $=(\mathrm{MIC}$ or MFC of compound 
A in combination with compound $\mathrm{B} / \mathrm{MIC}$ or MFC of compound $\mathrm{A}$, alone $)+(\mathrm{MIC}$ or MFC of compound $\mathrm{B}$ in combination with compound $\mathrm{A} / \mathrm{MIC}$ or $\mathrm{MFC}$ of compound $\mathrm{B}$, alone). Interactions were defined as: "synergistic" (FICI or FFCI $\leq 0.5$ ) or "indifferent” (FICI or FFCI > 0.5-4) (Odds, 2003).

\section{GROWTH RECOVERY TEST IN ASPERGILLUS STRAINS TREATED WITH HIGH TEMPERATURES: AGAR PLATE-BIOASSAY}

Agar plate-based bioassay was performed to evaluate differential susceptibility of Aspergillus strains to high temperatures. First, fungal conidia $\left(5 \times 10^{3}\right)$ were spotted on PDA (see above for method), and were initially incubated at four different temperatures (moderate: $30,35^{\circ} \mathrm{C}$; high: $45,55^{\circ} \mathrm{C}$ ). Triplicate PDA plates were then removed from each temperature $\left(30,35,45\right.$, or $55^{\circ} \mathrm{C}$ ) at day $1,2,3$, and 4 , and were transferred to $30^{\circ} \mathrm{C}$ for additional $6,5,4$, and 3 days of growth, respectively, resulting in a total of 7 days of incubation for each treatment (i.e., 1 day growth at $55^{\circ} \mathrm{C}+6$ days growth at $30^{\circ} \mathrm{C}=$ Total 7 days growth, 2 days growth at $55^{\circ} \mathrm{C}+5$ days growth at $30^{\circ} \mathrm{C}=$ Total 7 days growth, 3 days growth at $55^{\circ} \mathrm{C}+4$ days growth at $30^{\circ} \mathrm{C}=$ Total 7 days growth, 4 days growth at $55^{\circ} \mathrm{C}+3$ days growth at $30^{\circ} \mathrm{C}=$ Total 7 days growth). For controls, Aspergillus strains were grown solely at respective temperature $\left(30,35,45\right.$, or $\left.55^{\circ} \mathrm{C}\right)$ for 7 days. The level of growth recovery at $30^{\circ} \mathrm{C}$ was evaluated based on fungal radial growth as described above.

\section{GROWTH RECOVERY TEST IN CELL WALL INTEGRITY MUTANTS OF SACCHAROMYCES CEREVISIAE TREATED WITH OG: YEAST DILUTION BIOASSAY}

To determine the effect of OG on the cell wall-integrity system of fungi, sorbitol recovery tests were performed using Petri plate-based yeast dilution bioassays. Ten-fold diluted, i.e., $10^{0}$ $\left(1 \times 10^{6}\right.$ cells $), 10^{-1}, 10^{-2}, 10^{-3}, 10^{-4}, 10^{-5}$, strains of $S$. cerevisiae BY4741 (WT), bck1 $\Delta$ and slt2 $\Delta$ were spotted on: (1) SG only, (2) SG + caffeine $(5 \mathrm{mM}$; a positive control for cell wall disruption) or SG + OG $(0.03,0.04,0.05,0.06 \mathrm{mM})$ (Testing sensitivity of $b c k 1 \Delta$ and slt $2 \Delta$ mutants to compounds), and (3) SG + sorbitol $(0.5 \mathrm{M})+$ caffeine or OG (Testing growth recovery of $b c k 1 \Delta$ and slt $2 \Delta$ mutants by sorbitol). Cell growth was monitored for 5-7 days. If the growth score on the sorbitol-containing medium was higher than that on the "no sorbitol" medium, OG was considered to negatively affect cell wall integrity.

\section{AFLATOXIN ASSAYS}

For aflatoxin analysis, spore suspensions (200 spores) were inoculated onto the center of PDA plates. Cells were grown at $30^{\circ} \mathrm{C}$ for 7 days with or without OG (OG concentration: 0.025, 0.05, 0.1 mM; added directly into PDA), with each treatment in triplicate. Aflatoxins were quantitated as described previously (Rodriguez and Mahoney, 1994). Aflatoxin standard solutions $\left(\mathrm{AFB}_{1}, \mathrm{AFB}_{2}\right.$, $\mathrm{AFG}_{1}, \mathrm{AFG}_{2}$ ), used for the quantification of aflatoxins from OGtreated samples, were prepared as described in AOAC 971.22 (AOAC International, 2005).

\section{KOJIC ACID ASSAYS}

To examine whether the cellular secondary-product metabolism other than aflatoxin production is normal in the atoxigenic strains used in this study (namely, A. flavus 21882, 18543), we determined kojic acid (KA) production in these atoxigenic strains. A. flavus 3357 and 4212, toxigenic strains, were used as controls for KA production. Fungal spores $\left(1 \times 10^{5}\right.$ spores per $100 \mu \mathrm{L}$, $0.05 \%$ Tween 80 ) were inoculated into $50 \mathrm{~mL}$ potato dextrose broth, and were incubated at $30^{\circ} \mathrm{C}$ without shaking. KA production was measured from the culture media using an HPLC system consisting of a degasser, autosampler, quaternary pump, and photodiode array detector (Agilent 1100, Santa Clara, CA USA). Culture media aliquots of $1 \mathrm{~mL}$ were filtered through $0.45 \mu \mathrm{m}$ sterile nylon $25 \mathrm{~mm}$ syringe filters (Fisherbrand, Thermo Fisher Scientific, Waltham, MA, USA), with injection volumes of $20 \mu \mathrm{L}$ on a $4.6 \times 250 \mathrm{~mm}$ Inertsil $5 \mu \mathrm{m}$ ODS-3 column (GL Sciences, Torrance, CA, USA) using an isocratic mobile phase consisting of $\mathrm{MeOH} / 0.1 \% \mathrm{H}_{3} \mathrm{PO}_{4}(25: 75, \mathrm{v} / \mathrm{v})$ at a flow rate of $1 \mathrm{~mL}$ per minute. KA quantitation was based on UV detection at $265 \mathrm{~nm}$. HPLC quantification of KA was linear in the range of $0.02-4.00 \mu \mathrm{g}$ per $20 \mu \mathrm{L}$, with a retention time of $5.4 \mathrm{~min}$.

\section{STATISTICAL ANALYSIS}

Statistical analysis (student's $t$-test) was performed based on "Statistics to use" (Kirkman, 2014), where $p<0.05$ was considered significant.

\section{RESULTS \\ SUSCEPTIBILITY OF ASPERGILLUS STRAINS TO OG OR VT: AGAR PLATE-BIOASSAY}

As shown in Table 2, OG possessed much higher antifungal activity compared to VT. The average MICs of OG was $0.4 \mathrm{mM}$, while that of VT was higher than $4.8 \mathrm{mM}$ (viz. more than 10 times higher antifungal activity of $\mathrm{OG})$.

Table 2 | Differential sensitivity of Aspergillus strains to OG, VT, or high temperature $\left(55^{\circ} \mathrm{C}\right)$.

\begin{tabular}{|c|c|c|c|}
\hline Strains & OG (mM) & VT (mM) & $\begin{array}{l}\text { High temperature } \\
\text { recovery from } 55^{\circ} \mathrm{C} \\
(\text { Days) })^{\mathrm{a}}\end{array}$ \\
\hline A. flavus 3357 & 0.40 & $>5.0^{\mathrm{b}}$ & 0 \\
\hline A. flavus 4212 & 0.40 & $>5.0$ & 0 \\
\hline A. flavus 21882 & 0.50 & $>5.0$ & 0 \\
\hline A. flavus 18543 & 0.45 & $>5.0$ & 1 \\
\hline A. parasiticus 5862 & 0.40 & $>5.0$ & 1 \\
\hline A. parasiticus 2999 & 0.50 & $>5.0$ & 1 \\
\hline A. fumigatus AF293 & 0.35 & 4.5 & 4 \\
\hline A. fumigatus sakAs & 0.30 & 4.5 & 4 \\
\hline A. fumigatus mpkCs & 0.30 & 4.5 & 4 \\
\hline Average & 0.40 & $>4.8$ & 1.7 \\
\hline$t$-test & $p<0.005^{c}$ & - & - \\
\hline
\end{tabular}

Concentrations ( $m M$ ) are MICs examined on PDA plates.

a Maximum day(s) of incubation at $55^{\circ} \mathrm{C}$, which can result in growth recovery of fungi at $30^{\circ} \mathrm{C}$.

${ }^{b} V T$ was tested up to $5.0 \mathrm{mM}$. For statistical calculation (student's t-test) purpose, $10.0 \mathrm{mM}$ (doubling of $5.0 \mathrm{mM}$ ) was used.

${ }^{c}$ Student's t-test for paired data $\left(M I C_{O G}\right)$ was vs. MIC VT determined in nine strains. 
Results also indicated differential susceptibility (namely, different MIC level) of Aspergillus strains to the treatments, where: (1) All A. fumigatus strains (WT, sakA $\Delta, m p k C \Delta$ ) were more sensitive to either OG or VT compared to other Aspergillus strains ( $p<0.05$ for OG, $p<0.005$ for VT), (2) A. fumigatus MAPK mutants (sakA $\Delta, m p k C \Delta)$ were more sensitive to OG compared to the WT $(p<0.005)$. Although MICs of VT for all A. fumigatus strains were similar (MIC $\mathrm{VT}$ : $4.5 \mathrm{mM})$, the level of growth of MAPK mutants was also lower than the WT (see below; Table 3). Thus, results indicated MAPK mutants lack the defense mechanism to protect fungal cells from the toxicity generated by redox-active benzo derivatives, (3) A. flavus 21882 and A. parasiticus 2999 were more tolerant to OG compared to other Aspergillus strains $(p<0.05)$, (4) A. flavus 3357, 4212 and A. parasiticus 5862 showed similar levels of susceptibility to OG, and (5) A. flavus 3357, 4212, 21882, 18543 and $A$. parasiticus 5862, 2999 also showed similar levels of susceptibility to VT (up to $5 \mathrm{mM}$ ).

\section{SUSCEPTIBILITY OF ASPERGILLUS TO HIGH TEMPERATURES}

Heat responses of Aspergillus strains were compared to their responses to benzo derivatives. Aspergillus strains were treated with moderate $\left(30,35^{\circ} \mathrm{C}\right)$ to high $\left(45,55^{\circ} \mathrm{C}\right)$ temperatures, and were then transferred to $30^{\circ} \mathrm{C}$ for growth recovery. From the pathogenicity perspective, A. flavus shares agro-infectivity with A. parasiticus, while $A$. flavus shares human-infectivity with $A$. fumigatus (Figure 2A). As shown in Figure 2B, A. fumigatus strains, both WT and MAPK mutants, were much more tolerant to high temperature $\left(55^{\circ} \mathrm{C}\right)$, compared to other Aspergillus strains examined. For example, A. fumigatus strains did not germinate on PDA when they were maintained at $55^{\circ} \mathrm{C}$ for 7 days. However, A. fumigatus treated with heat $\left(55^{\circ} \mathrm{C}\right)$ for $1-4$ days could recover the growth after incubation at $30^{\circ} \mathrm{C}$, while A. flavus 3357,4212 and 21882 could not recover their growth even after 1 day-heat treatment at $55^{\circ} \mathrm{C}$ (see Table 2 for summary). The remaining Aspergillus strains $(18543,5862,2999)$ showed growth recovery only with 1 day-heat treatment at $55^{\circ} \mathrm{C}$. A. fumigatus MAPK mutants were marginally more sensitive to heat $\left(55^{\circ} \mathrm{C}\right)$ (i.e., $2-$ $10 \%$ less radial growth during recovery w/ 3-4 day-treatment at $55^{\circ} \mathrm{C}$ ) compared to the WT (Figure 2B).

The order of susceptibility of Aspergillus strains to high temperature $\left(55^{\circ} \mathrm{C}\right)$ (higher susceptibility to lower susceptibility) was: A. flavus 3357, 4212, $21882>$ A. flavus 18543, A. parasiticus 5862, $2999>$ A. fumigatus strains. Therefore, like in benzo treatments, Aspergillus strains showed differential susceptibility to high temperature $\left(55^{\circ} \mathrm{C}\right)$, where $A$. fumigatus strains were the most heattolerant species among Aspergillus strains tested. However, there was no direct correlation in fungal responses between benzo and heat treatments, indicating the mechanism of antifungal action of benzo analog(s) is considered to be different from that of heat treatment (see Table 2). [Aspergillus strains were also sensitive to

Table 3 | Responses of A. fumigatus WT and MAPK mutants to the treatments of benzo derivatives w/o or w/Kre-Me (25 $\mu$ M) $)^{a}$.

\begin{tabular}{|c|c|c|c|c|c|c|c|}
\hline VT (mM) & AF293 \% & sakA $\boldsymbol{A} \%$ & $m p k C \Delta \%$ & OG (mM) & AF293 \% & 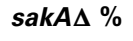 & mpkCA \% \\
\hline \multicolumn{8}{|c|}{ w/o Kre-Me } \\
\hline 0.0 & 100 & 100 & 100 & 0.000 & 100 & 100 & 100 \\
\hline 0.5 & 100 & 100 & 96 & 0.025 & 86 & 70 & 74 \\
\hline 1.0 & 100 & 98 & 96 & 0.050 & 70 & 60 & 66 \\
\hline 1.5 & 100 & 96 & 94 & 0.100 & 54 & 48 & 52 \\
\hline 2.0 & 100 & 92 & 92 & 0.150 & 46 & 38 & 42 \\
\hline 2.5 & 100 & 92 & 92 & 0.200 & 36 & 24 & 28 \\
\hline 3.0 & 96 & 84 & 86 & 0.250 & 28 & few & few \\
\hline 3.5 & 75 & 69 & 72 & 0.300 & few & 0 & 0 \\
\hline 4.0 & few $w^{b}$ & few & few & 0.350 & 0 & 0 & 0 \\
\hline 4.5 & 0 & 0 & 0 & 0.400 & 0 & 0 & 0 \\
\hline 5.0 & 0 & 0 & 0 & 0.450 & 0 & 0 & 0 \\
\hline \multicolumn{8}{|c|}{ w/Kre-Me } \\
\hline 0.0 & 100 & 104 & 109 & 0.000 & 100 & 104 & 109 \\
\hline 0.5 & 83 & 96 & 96 & 0.025 & 52 & few & few \\
\hline 1.0 & 70 & 78 & 83 & 0.050 & 0 & 0 & 0 \\
\hline 1.5 & 61 & 74 & 74 & 0.100 & 0 & 0 & 0 \\
\hline 2.0 & 52 & 65 & 70 & 0.150 & 0 & 0 & 0 \\
\hline 2.5 & 43 & 57 & 65 & 0.200 & 0 & 0 & 0 \\
\hline 3.0 & 0 & 48 & 48 & 0.250 & 0 & 0 & 0 \\
\hline 3.5 & 0 & few & few & 0.300 & 0 & 0 & 0 \\
\hline 4.0 & 0 & 0 & 0 & 0.350 & 0 & 0 & 0 \\
\hline 4.5 & 0 & 0 & 0 & 0.400 & 0 & 0 & 0 \\
\hline 5.0 & 0 & 0 & 0 & 0.450 & 0 & 0 & 0 \\
\hline
\end{tabular}

${ }^{a}$ Data shown in the table are \% radial growth of fungi compared to control (no treatment). SD $<5 \%$. No visible cell growth (0\%) is in bold.

${ }^{b}$ Few: Only few colonies appeared. 


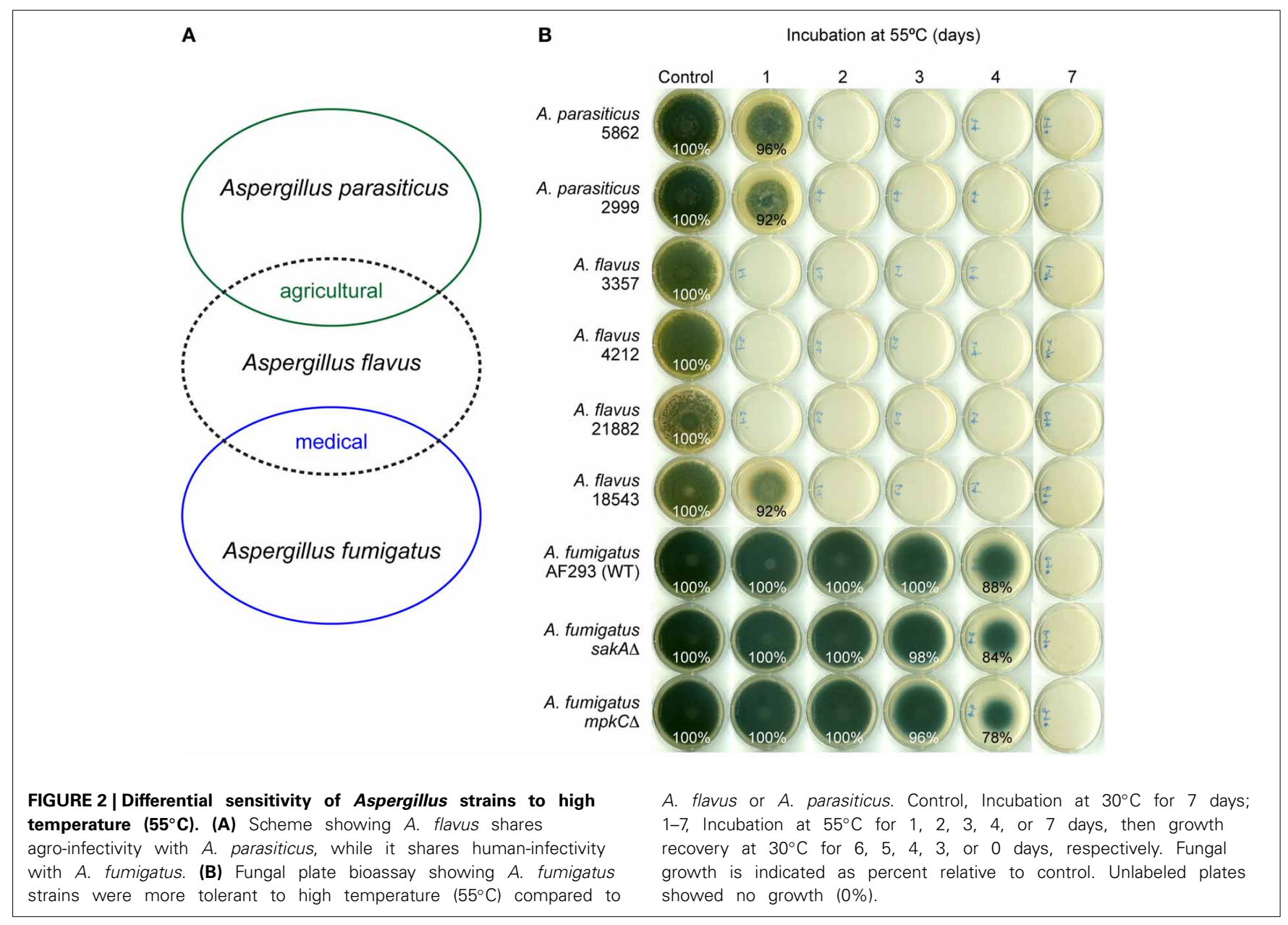

$45^{\circ} \mathrm{C}$. However, all Aspergillus strains recovered their growth after transfer from 45 to $30^{\circ} \mathrm{C}$ (see Figure S1 for exemplary bioassay with $A$. flavus). As expected, Aspergillus strains grew normally at the moderate temperatures $\left(30\right.$ and $35^{\circ} \mathrm{C}$ ) (Figure S1)].

\section{SUSCEPTIBILITY OF A. FUMIGATUS TO CHEMOSENSITIZATION}

Chemosensitizing capability of OG or VT to Kre-Me was tested in A. fumigatus strains by using agar plate-bioassays. Results showed that: (1) When Kre-Me was co-applied with VT, the MIC of VT was lowered from $4.5 \mathrm{mM}$ to $3.0 \mathrm{mM}_{\mathrm{MAPK}}$ or $4.0 \mathrm{mM}_{\mathrm{WT}}$, respectively (Table 3), and (2) When Kre-Me was co-applied with OG, the MIC of OG was lowered from $0.3 \mathrm{mM}_{\mathrm{MAPK}}$ or $0.35 \mathrm{mM}_{\mathrm{WT}}$ to $0.05 \mathrm{mM}_{\mathrm{MAPKandWT}}$. Therefore, both OG and VT possessed chemosensitizing capability to Kre-Me in A. fumigatus strains, where OG possessed much higher chemosensitizing capacity (viz. needed $\sim 10$ times lower concentration for chemosensitization; $p<0.005$ ) than VT (Table 3 ).

Noteworthy is that the A. fumigatus MAPK mutants were more tolerant to Kre-Me (Table 3), where: (1) The level of radial growth of MAPK mutants with independent treatment of Kre-Me was marginally greater (4-9\% more growth) than the WT, and (2) When VT was co-applied with Kre-Me $(25 \mu \mathrm{M}), \mathrm{MIC}_{\mathrm{VT}}$ was $3.0 \mathrm{mM}$ for the WT, while that of MAPK mutants was $4.0 \mathrm{mM}$ (namely, higher concentration of VT is needed compared to the WT) during this chemosensitization (Table 3). Therefore, although VT-mediated chemosensitization was achieved in all $A$. fumigatus strains, results showed relatively higher tolerance of MAPK mutants to "Kre-Me + VT" compared to the WT [see below (Table 4) for relative tolerance of MAPK mutants to "Kre$\mathrm{Me}+\mathrm{BHAM"} \mathrm{compared} \mathrm{to} \mathrm{the} \mathrm{WT].} \mathrm{However,} \mathrm{Kre-Me} \mathrm{tolerance}$ of A. fumigatus MAPK mutants was completely abolished by OG (Table 3).

Co-application of OG or VT with Kre-Me also enhanced growth inhibition in toxigenic strains of Aspergillus (A. flavus 3357, A. parasiticus 5862) (viz. either complete growth inhibition or reduced radial growth, depending on types of strains/combination of compounds; Figure 3). For example, the growth of $A$. parasiticus 5862 was completely inhibited by Kre$\mathrm{Me}+\mathrm{VT}$, while a similar level of growth inhibition in A. flavus 3357 could be achieved by Kre-Me + OG (Figure 3). Independent treatment of each compound alone at the same concentration did not achieve such a level of growth inhibition. Thus, results indicated differential susceptibility of each strain to different combinations of antifungal agents, where 3357 showed higher susceptibility (complete growth inhibition) to Kre-Me + OG, whereas 5862 was more susceptible to Kre-Me + VT (complete growth inhibition). As observed in A. fumigatus, OG possessed much higher antifungal potency in toxigenic Aspergillus strains 
Table 4 | Antifungal chemosensitization of OG (mM) or BHAM (mM) to Kre-Me $\left(\mu \mathrm{g} \mathrm{mL}^{-1}\right)$, tested against Aspergillus strains: summary of CLSI-based microdilution bioassays $(48 \mathrm{~h})^{\mathrm{a}}$.

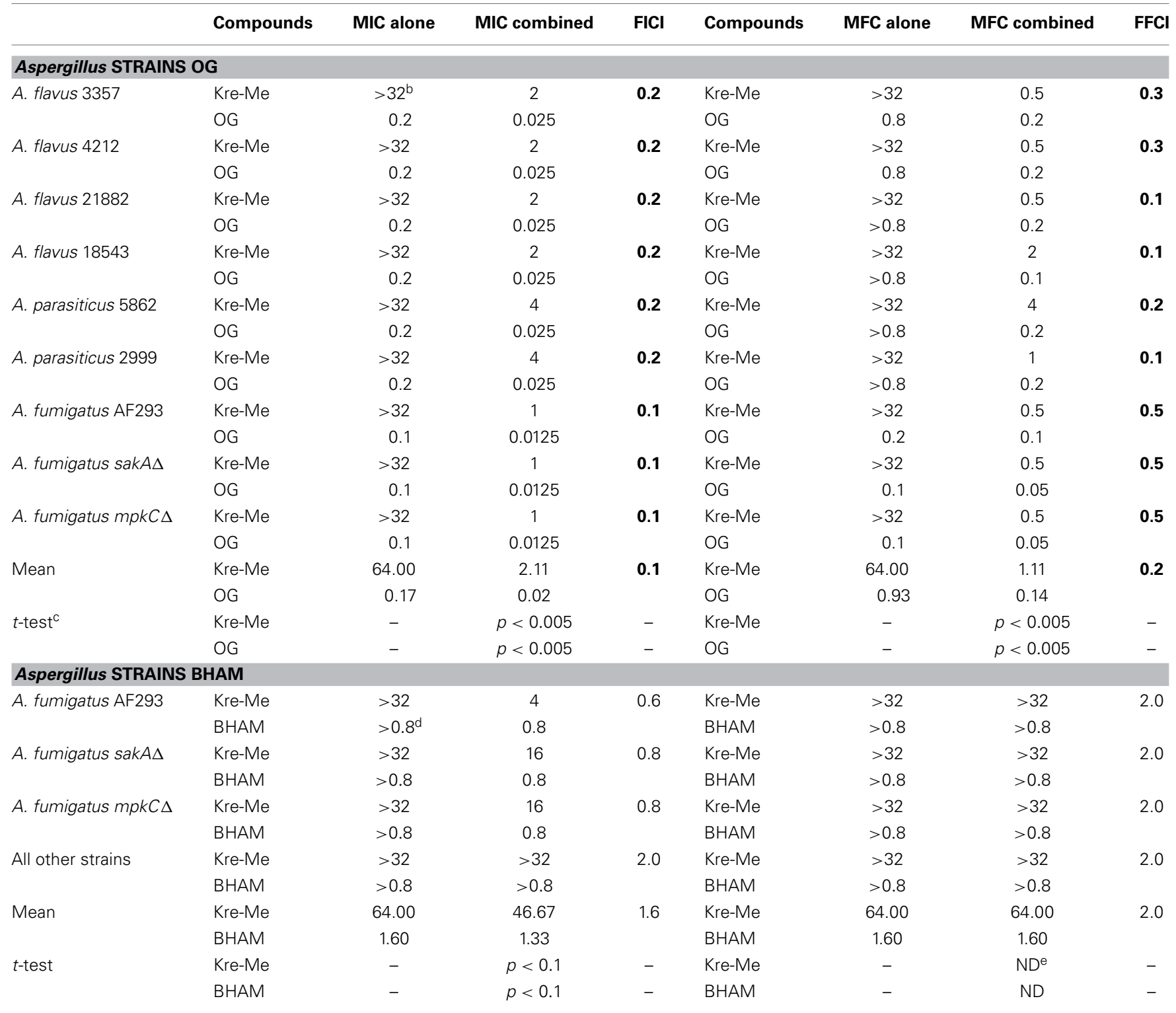

${ }^{a}$ MIC, Minimum inhibitory concentration; MFC, Minimum fungicidal concentration; FICl, Fractional Inhibitory Concentration Indices; FFCl, Fractional Fungicidal Concentration Indices. Synergistic FICls and FFCls are in bold.

${ }^{b}$ Kre-Me was tested up to $32 \mu \mathrm{g} \mathrm{mL}{ }^{-1}$. For calculation purpose, $64 \mu \mathrm{g} \mathrm{mL}^{-1}$ (doubling of $32 \mu \mathrm{g} \mathrm{mL}^{-1}$ ) was used.

${ }^{c}$ Student's t-test for paired data (combined, i.e., chemosensitization) was vs. mean MIC or MFC of each compound (alone, i.e., no chemosensitization) determined in strains.

${ }^{d}$ BHAM was tested up to $0.8 \mathrm{mM}$. For calculation purpose, $1.6 \mathrm{mM}$ (doubling of $0.8 \mathrm{mM}$ ) was used.

${ }^{e} N D$, Not determined (neutral interaction).

compared to VT (namely, $50 \mu \mathrm{M}_{\mathrm{OG}}$ vs. $3 \mathrm{mM}_{\mathrm{VT}}$, respectively, for achieving chemosensitization).

In CLSI liquid bioassay, co-application of Kre-Me with OG completely inhibited the growth of Aspergillus strains (100\% killing in MFC testing), where independent treatment of each compound alone at the same concentrations allowed the survival of fungi (Figures 4, 5). For MICs, "synergistic" FICIs (FICI $\leq 0.5$; see Materials and Methods for calculations) were found between OG and Kre-Me for all Aspergillus strains (Table 4). For MFCs, "synergistic" FFCIs (FFCI $\leq 0.5$ ) were also achieved by co-application of OG with Kre-Me for all Aspergillus strains tested (Table 4). Although there was increased antifungal activity of BHAM and Kre-Me when co-applied in A. fumigatus strains (WT, sakA $\Delta, m p k C \Delta)$ (FICI $=0.6-0.8$; Table 4), no calculated synergism was found in any of the Aspergillus strains tested with BHAM + Kre-Me (Table 4). As with VT + Kre-Me 


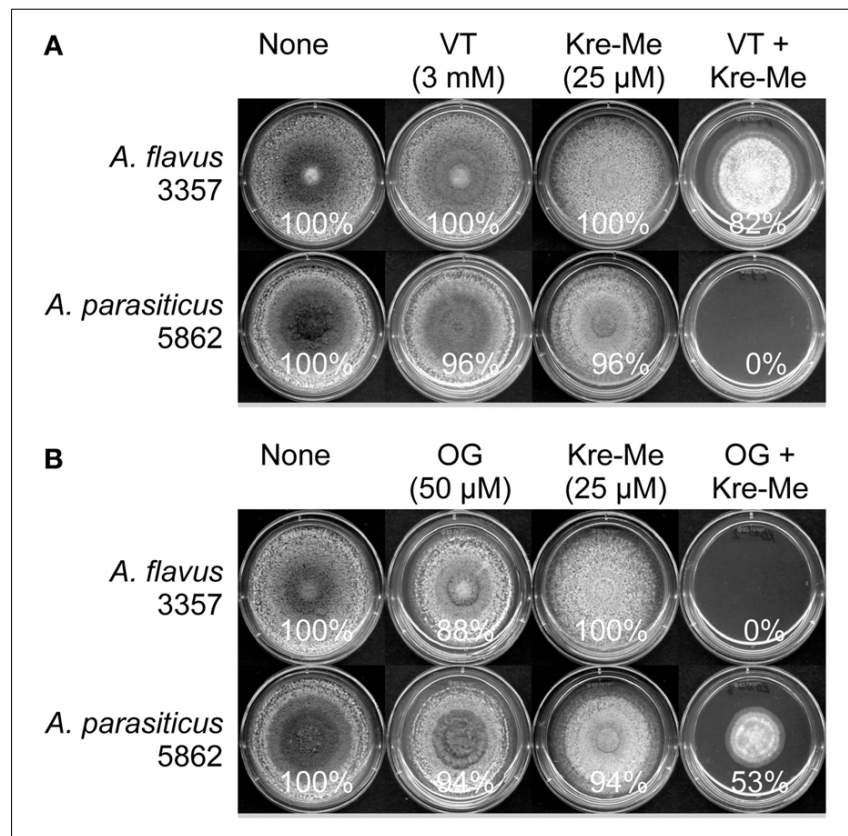

FIGURE 3 | Differential sensitivity of $\boldsymbol{A}$. flavus 3357 and $\boldsymbol{A}$. parasiticus 5862 to co-treatment of Kre-Me with VT or OG. (A) A. parasiticus 5862 was more sensitive to "Kre-Me + VT" compared to A. flavus 3357. (B) A. flavus 3357 showed higher sensitivity to "Kre-Me + OG" compared to $A$. parasiticus 5862. Results show differential sensitivity of each strain to different combinations of compounds.

(see above), A. fumigatus MAPK mutant also showed higher tolerance to "BHAM + Kre-Me" chemosensitization, where the value of MIC COMBINED of Kre-Me was $4 \mu \mathrm{g} \mathrm{mL}^{-1}$ for WT, while that for MAPK mutants was $16 \mu \mathrm{g} \mathrm{mL}^{-1}$, respectively, (viz. four times higher tolerance to Kre-Me) (Table 4). Noteworthy is that certain fungi with mutation(s) in the MAPK signaling pathway can also escape toxicity of the commercial fungicide fludioxonil (Kojima et al., 2004).

\section{GROWTH RECOVERY TEST IN CELL WALL INTEGRITY MUTANTS OF $\boldsymbol{S}$. CEREVISIAE TREATED WITH OG}

In sorbitol remediation bioassay, sensitivity of slt $2 \Delta$ and $b c k 1 \Delta$ to OG was alleviated by sorbitol. The growth rate of slt $2 \Delta$ and $b c k 1 \Delta$ on sorbitol-containing media was $100-1000$ times higher for caffeine or OG, respectively, compared to controls without sorbitol (Figure 6). Thus, the remediation by sorbitol indicates disruption of cell wall/membrane integrity in fungi is one contributing mechanism of how OG generates chemosensitization.

\section{EFFECT OF OG ON AFLATOXIN PRODUCTION}

When toxigenic strains of $A$. flavus and $A$. parasiticus were treated with OG (tested at 25,50,100 $\mu \mathrm{M}$ ), the highest reduction in aflatoxin production was observed at 25 or $50 \mu \mathrm{M}$ of OG, depending on types of strains. Aflatoxin production in OG-treated plates was reduced 4-30\% compared to non-treated control plates (Table 5).

\section{DISCUSSION}

In this study, nine Aspergillus strains, namely, four toxigenic strains of $A$. flavus and $A$. parasiticus, two atoxigenic strains of
A. flavus, and three A. fumigatus strains, WT and MAPK mutants (sakA $\Delta, m p k C \Delta)$, were examined for their responses to different treatments. The A. fumigatus sakA $\Delta$ (sakA gene deletion) is an osmotic/oxidative stress sensitive mutant, while the $m p k C \Delta$ (mpkC gene deletion) is a mutant of the polyalcohol sugar utilization system (Xue et al., 2004; Reyes et al., 2006). In a prior study, both sakA $\Delta$ and $m p k C \Delta$ mutants showed higher sensitivity to certain benzo derivatives compared to the WT (Kim et al., 2011). The molecular biological/genetic resources (such as gene deletion mutants) for A. flavus or A. parasiticus available are few in number. Hence, $A$. fumigatus sakA $\Delta$ and $m p k C \Delta$ mutants could serve as model strains for investigating potential modes of antifungal responses in congeners, such as A. flavus or A. parasiticus. Except for the incapability to produce aflatoxins, the atoxigenic strains A. flavus 21882 and 18543 could produce KA (Table S1), a different type of secondary metabolite produced by $A$. flavus and A. parasiticus. Thus, the cellular secondary-product metabolism other than aflatoxin production is thought to be normal in the atoxigenic strains examined in this study.

Results showed that OG- or VT-based chemosensitization could enhance antifungal activity of Kre-Me in Aspergillus strains, where Aspergillus strains tested were sensitive to Kre-Me + OG or VT. OG was a more potent chemosensitizing agent than VT or BHAM to Kre-Me, where the concentration of OG necessary to achieve antifungal "synergism" was much lower $(\geq 10$ times lower) than the other compounds. When fungi are treated with Kre-Me, cellular AOX allows completion of electron transfer and ATP production via the MRC, thus resulting in overcoming the toxicity triggered by Kre-Me (or other MRC inhibitors) (Costade-Oliveira et al., 2012; Inoue et al., 2012). Therefore, AOX inhibitors, such as BHAM, have the effect to enhance the activity of Kre-Me (or other MRC inhibitors) when co-applied. The OGbased chemosensitization to Kre-Me, performed in this study, indicated that the AOX-inhibitory activity of OG (Sierra-Campos et al., 2009; Robles-Martinez et al., 2013) is much higher than that of the conventional AOX inhibitor, BHAM. Noteworthy is that the efficacy of OG-based chemosensitization to Kre-Me (which was "synergistic") was higher compared to the prior chemosensitization test with "2-hydroxy-5-methoxybenzaldehyde (phenolic) + antimycin A (MRC inhibitor)" (Kim et al., 2011), in which the level of compound interaction was "additive/indifferent" but not "synergistic."

The inhibition of MRC not only disrupts cellular ATP production, but also triggers oxidative stress, which results from abnormal leakage of electrons from the MRC (Fujita et al., 2004; Ruy et al., 2006). The escaped electrons cause oxidative damage to cellular components, such as cell membranes. Therefore, the enhanced oxidative stress generated by both MRC inhibitor (Kre$\mathrm{Me}$ ) and the redox-active phenolic derivative (OG) would result in increased growth inhibition of fungi.

Caffeine (a "control" reagent used in the cell wall/membrane integrity bioassay) tends to disorganize cell surface in fungi. Thus, fungi having abnormalities in cell surface integrity show increased sensitivity to caffeine treatment (Lussier et al., 1997). Caffeine also activates the protein kinase $\mathrm{C}$ (PKC) pathway, where the MAPK pathway genes $S L T 2$ and $B C K 1$ play key roles for maintaining cell wall integrity (Martin et al., 2000). Therefore, SLT2 and BCK1 

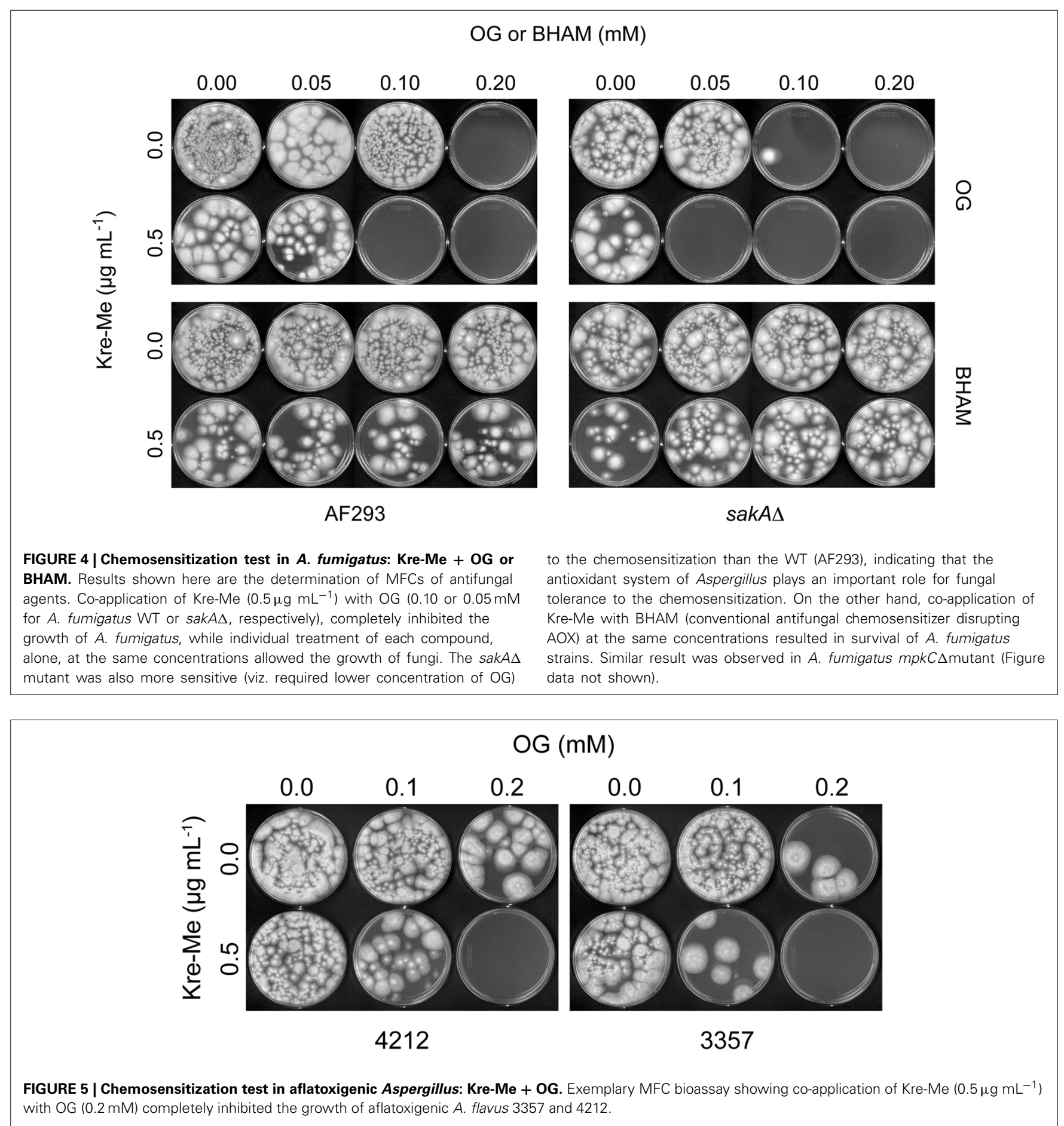

gene deletion mutants $($ slt $2 \Delta$ and $b c k 1 \Delta)$ are hypersensitive to caffeine treatment, while caffeine sensitivity of $s l t 2 \Delta$ and $b c k 1 \Delta$ could be alleviated by sorbitol (Martin et al., 2000; Ferreira et al., 2006). As shown in this study, OG also disrupted cell wall integrity, where $S$. cerevisiae MAPK pathway mutants (slt2 $\Delta$, $b c k 1 \Delta$ ) showed enhanced sensitivity to OG, while this sensitivity was remedied by sorbitol.

OG possessed some moderate level of antiaflatoxigenic activity, where $4-30 \%$ of reduction in aflatoxin production was achieved depending on types of toxigenic Aspergillus strains. In a prior study, more than $95 \%$ of inhibition in aflatoxin production could be achieved with caffeic acid, which is another type of phenolic compound (Kim et al., 2008). Modulation of the expression of antioxidant genes, such as alkyl hydroperoxide reductases (Ahp1) that detoxify organic peroxides, has been the mechanism of antiaflatoxigenic activity of caffeic acid (Kim et al., 2008). However, caffeic acid did not exhibit potent antifungal activity in the same study, indicating antimycotoxigenic activity 


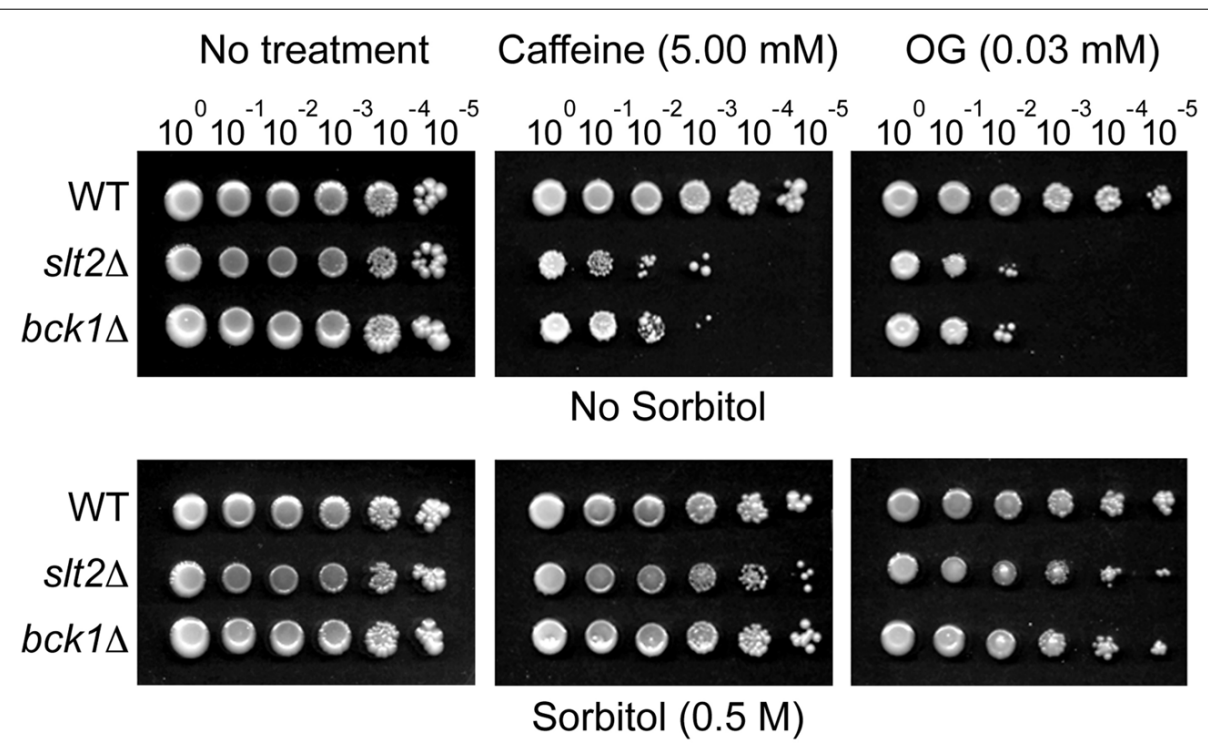

FIGURE 6 | Yeast cell-dilution bioassay showing sensitivity of $S$. cerevisiae slt2 $\Delta$ and bck $1 \Delta$ mutants to caffeine (5 mM; control) and OG (0.03 mM) was remediated by sorbitol. Similar remediation by sorbitol was found from treatment with higher concentration $(0.04,0.05,0.06 \mathrm{mM})$ of $\mathrm{OG}$ (results not shown).

Table 5 | Antiaflatoxigenic activity of OG in A. flavus 3357, 4212, A. parasiticus 2999 (OG at $25 \mu \mathrm{M}$ ) and A. parasiticus 5862 (OG at $50 \mu \mathrm{M}$ ).

\begin{tabular}{|c|c|c|c|c|c|}
\hline & & A. flavus 3357 & A. flavus 4212 & A. parasiticus 2999 & A. parasiticus 5862 \\
\hline $\mathrm{AFB}_{1}$ & OG & $5.260 \pm 0.663$ & $5.460 \pm 0.561$ & $14.900 \pm 1.119$ & $15.200 \pm 1.271$ \\
\hline \multirow[t]{2}{*}{$\mathrm{AFB}_{2}$} & No OG & $0.090 \pm 0.020$ & $0.031 \pm 0.010$ & $0.290 \pm 0.046$ & $0.290 \pm 0.112$ \\
\hline & OG & $0.066 \pm 0.015$ & $0.026 \pm 0.005$ & $0.260 \pm 0.036$ & $0.240 \pm 0.033$ \\
\hline \multirow[t]{3}{*}{$\mathrm{AFG}_{1}$} & No OG & $N D^{a}$ & ND & $4.030 \pm 0.612$ & $4.030 \pm 1.581$ \\
\hline & OG & ND & ND & $3.720 \pm 0.510$ & $3.870 \pm 0.608$ \\
\hline & \% Reduction & & & -8 & -4 \\
\hline \multirow[t]{2}{*}{$\mathrm{AFG}_{2}$} & No OG & ND & ND & $0.090 \pm 0.015$ & $0.100 \pm 0.040$ \\
\hline & OG & ND & ND & $0.070 \pm 0.010$ & $0.070 \pm 0.016$ \\
\hline
\end{tabular}

Aflatoxin amount produced: $\mu \mathrm{g}$ per $\mathrm{cm}^{2}$ of fungal mat.

${ }^{a} N D$, Not detectable.

of phenolic compounds is not always parallel to their antifungal activity or vice versa. Although OG possessed potent antifungal activity, as determined in this study, its antiaflatoxigenic capacity is not comparable to other types of phenolic agents, such as caffeic acid (e.g., reduction of aflatoxin production: $4-30 \%$ w/ OG vs. $>95 \% \mathrm{w} /$ caffeic acid). Therefore, the intervention of either aflatoxin production or the growth of fungal pathogens could be achieved by treating or modulating different cellular targets, such as antioxidant enzymes (Ahp1) for mycotoxin control or MRC and cell wall/membrane integrity, etc., for fungal growth control, respectively.

"Compound or chemosensitization—strain specificity" exists with OG, reflecting differential susceptibility of Aspergillus strains to the treatments. Of note, cellular signaling system, such as histidine kinase receptors, MAPK, etc., was involved in differential susceptibility of fungi to fungicide or drugs (Ochiai et al., 2002; Kojima et al., 2004; Chapeland-Leclerc et al., 2007). For example, (1) Three histidine kinase receptors were differentially involved in drug sensitivity or stress adaptation of the opportunistic yeast Candida lusitaniae (Chapeland-Leclerc et al., 2007), (2) The pathogenic yeast $C$. albicans (containing multiple histidine kinase genes) were sensitive to the fungicides iprodione and fludioxonil, while the model yeast $S$. cerevisiae (having only one histidine kinase gene) showed insensitivity to these fungicides (Ochiai et al., 2002), and (3) Intact MAPK signaling system is required for the effective antifungal activity of fludioxonil, where MAPK mutants of the fungal pathogen Colletotrichum lagenarium exhibited increased resistance to the fungicide. Thus, it is thought 
that (1) different set-up of signaling components in various species of Aspergillus, and/or (2) modification or mutation in cellular signaling system during evolution/stress adaptation could be possible mechanisms of actions for differential susceptibility of Aspergillus strains to fungicides or environmental stresses (such as Kre-Me tolerance of $A$. fumigatus MAPK mutants or heat responses, as determined in this study). Determination of precise mechanism of differential susceptibility to the treatments warrants future study.

As with agricultural application, the MRC is recently considered as a new antifungal target for clinical antimycotic therapy. Examples include: (1) MRC inhibitors increased fluconazole susceptibility of both patient and laboratory isolates of C. albicans (Sun et al., 2013); (2) co-application of antimycin A (another MRC-inhibitory drug) and BHAM significantly enhanced antifungal potency of posaconazole and itraconazole (Shirazi and Kontoyiannis, 2013), where the antifungal activity of the drugs was determined as "fungicidal" in mucormycosiscausing Rhizopus oryzae; (3) inhibition of MRC of C. parapsilosis, causative agent for neonatal and device-related infections, enhances susceptibility of the pathogen to caspofungin, which is a cell wall-disrupting drug [(Chamilos et al., 2006) and references therein].

Application of chemosensitizing agents, such as OG, would lower the effective dosage of MRC-inhibitory drugs or fungicides (e.g., strobilurins). This approach thus, lowers negative side effects of MRC inhibitors and/or prevents fungal tolerance to strobilurins, as described in this study. Consequently, lowered dosage level of antifungal agents would render treatment or agricultural practice, such as control of aflatoxin-producing Aspergillus strains, less expensive and safer.

In conclusion, OG and/or VT exhibit potential to serve as safe antifungal chemosensitizers that in concert with Kre-Me greatly potentiate antifungal activity. This capacity was shown to be effective in most of the Aspergillus strains tested in this study. Moreover, OG was shown to also have moderate antiaflatoxigenic activity.

\section{ACKNOWLEDGMENTS}

This research was conducted under USDA-ARS CRIS Project 5325-42000-037-00D. We thank Dr. Gregory S. May at the University of Texas M.D. Anderson Cancer Center, Houston, TX for kindly providing us $A$. fumigatus sakAs and $m p k C \Delta$ strains.

\section{SUPPLEMENTARY MATERIALS}

The Supplementary Material for this article can be found online at: http://www.frontiersin.org/journal/10.3389/fmicb.2014. 00087/abstract

\section{REFERENCES}

Agarwal, A. K., Tripathi, S. K., Xu, T., Jacob, M. R., Li, X. C., and Clark, A. M. (2012). Exploring the molecular basis of antifungal synergies using genomewide approaches. Front. Microbiol. 3:115. doi: 10.3389/fmicb2012.00115

AOAC International. (2005). Official Methods of Analysis of AOAC International. 18th Edn. Official method 971.22. Gaithersburg, MD: AOAC International.

Aspergillus Comparative Database. Available online at: www.broadinstitute.org/ annotation/genome/aspergillus_group/MultiHome.html (Accessed: 9 January 2014).
Aspergillus flavus NRRL 21882 (006500) Fact Sheet. Available online at: www.epa.gov/pesticides/chem_search/reg_actions/registration/fs_PC-006500_2 5-Nov-09.pdf (Accessed: 8 January 2014).

Bartlett, D. W., Clough, J. M., Godwin, J. R., Hall, A. A., Hamer, M., and ParrDobrzanski, B. (2002). The strobilurin fungicides. Pest Manag. Sci. 58, 649-662. doi: $10.1002 /$ ps.520

Beekrum, S., Govinden, R., Padayachee, T., and Odhavet, B. (2003). Naturally occurring phenols: a detoxification strategy for fumonisin $\mathrm{B}_{1}$. Food Addit. Contam. 20, 490-493. doi: 10.1080/0265203031000098678

Campbell, B. C., Chan, K. L., and Kim, J. H. (2012). Chemosensitization as a means to augment commercial antifungal agents. Front. Microbiol. 3:79. doi: 10.3389/fmicb.2012.00079

Campbell, B. C., Molyneux, R. J., and Schatzki, T. F. (2003). Current research on reducing pre- and post-harvest aflatoxin contamination of U. S. almond, pistachio and walnut. J. Toxicol. Toxin Rev. 22, 225-266. doi: 10.1081/TXR120024093

Chamilos, G., Lewis, R. E., and Kontoyiannis, D. P. (2006). Inhibition of Candida parapsilosis mitochondrial respiratory pathways enhances susceptibility to caspofungin. Antimicrob. Agents Chemother. 50, 744-747. doi: 10.1128/AAC.50.2.744-747.2006

Chapeland-Leclerc, F., Paccalletm, P., Ruprich-Robert, G., Reboutier, D., Chastin, C., and Papon, N. (2007). Differential involvement of histidine kinase receptors in pseudohyphal development, stress adaptation, and drug sensitivity of the opportunistic yeast Candida lusitaniae. Eukaryot. Cell 6, 1782-1794. doi: 10.1128/EC.00155-07

Clemons, K. V., Miller, T. K., Selitrennikoff, C. P., and Stevens, D. A. (2002). fos-1, a putative histidine kinase as a virulence factor systemic aspergillosis. Med. Mycol. 40, 259-262. doi: 10.1080/714031112

Clinical and Laboratory Standards Institute (CLSI). (2008). Reference Method for Broth Dilution Antifungal Susceptibility Testing of Filamentous Fungi: Approved Standard-Second Edition. CLSI Document M38-A2. Wayne, PA: Clinical and Laboratory Standards Institute.

Cools, H. J., and Hammond-Kosack, K. E. (2013). Exploitation of genomics in fungicide research: current status and future perspectives. Mol. Plant Pathol. 14, 197-210. doi: 10.1111/mpp.12001

Costa-de-Oliveira, S., Sampaio-Marques, B., Barbosa, M., Ricardo, E., Pina-Vaz, C., Ludovico, P., et al. (2012). An alternative respiratory pathway on Candida krusei: implications on susceptibility profile and oxidative stress. FEMS Yeast Res. 12, 423-429. doi: 10.1111/j.1567-1364.2012.00789.x

Dagnas, S., and Membré, J. M. (2013). Predicting and preventing mold spoilage of food products. J. Food Prot. 76, 538-551. doi: 10.4315/0362-028X.JFP12-349

de Dios, C. H., Román, E., Monge, R. A., and Pla, J. (2010). The role of MAPK signal transduction pathways in the response to oxidative stress in the fungal pathogen Candida albicans: implications in virulence. Curr. Protein Pept. Sci. 11, 693-703. doi: 10.2174/138920310794557655

Ehrlich, K. C., and Cotty, P. J. (2004). An isolate of Aspergillus flavus used to reduce aflatoxin contamination in cottonseed has a defective polyketide synthase gene. Appl. Microbiol. Biotechnol. 65, 473-478. doi: 10.1007/s00253-004-1670-y

Ellner, F. M. (2005). Results of long-term field studies into the effect of strobilurin containing fungicides on the production of mycotoxins in several winter wheat varieties. Mycotoxin Res. 21, 112-115. doi: 10.1007/BF02954432

Ferreira, C., Silva, S., van Voorst, F., Aguiar, C., Kielland-Brandt, M. C., Brandt, A., et al. (2006). Absence of Guplp in Saccharomyces cerevisiae results in defective cell wall composition, assembly, stability and morphology. FEMS Yeast Res. 6, 1027-1038. doi: 10.1111/j.1567-1364.2006.00110.x

Fujita, K., Tani, K., Usuki, Y., and Taniguchi, M. (2004). Growth inhibition dependent on reactive oxygen species generated by C9-UK-2A, a derivative of the antifungal antibiotic UK-2A, in Saccharomyces cerevisiae. J. Antibiot. (Tokyo) 57, 511-517. doi: 10.7164/antibiotics.57.511

Ghannoum, M. A., and Rice, L. B. (1999). Antifungal agents: mode of action, mechanisms of resistance, and correlation of these mechanisms with bacterial resistance. Clin. Microbiol. Rev. 12, 501-517.

Guillen, F., and Evans, C. S. (1994). Anisaldehyde and veratraldehyde acting as redox cycling agents for $\mathrm{H}_{2} \mathrm{O}_{2}$ production by Pleurotus eryngii. Appl. Environ. Microbiol. 60, 2811-2817.

Hamilton, A. J., and Holdom, M. D. (1999). Antioxidant systems in the pathogenic fungi of man and their role in virulence. Med. Mycol. 37, 375-389. doi: 10.1046/j.1365-280X.1999.00208.x 
Hawkins, L. K., Windham, G. L., and Williams, W. P. (2005). Effect of different postharvest drying temperatures on Aspergillus flavus survival and aflatoxin content in five maize hybrids. J. Food Prot. 68, 1521-1524.

Inoue, K., Tsurumi, T., Ishii, H., Park, P., and Ikeda, K. (2012). Cytological evaluation of the effect of azoxystrobin and alternative oxidase inhibitors in Botrytis cinerea. FEMS Microbiol. Lett. 326, 83-90. doi: 10.1111/j.15746968.2011.02438.x

Jacob, C. (2006). A scent of therapy: pharmacological implications of natural products containing redox-active sulfur atoms. Nat. Prod. Rep. 23, 851-863. doi: $10.1039 / \mathrm{b} 609523 \mathrm{~m}$

Keinath, A. P. (2009). Sensitivity to azoxystrobin in Didymella bryoniae isolates collected before and after field use of strobilurin fungicides. Pest Manag. Sci. 65, 1090-1096. doi: 10.1002/ps.1797

Kim, J. H., Chan, K. L., Mahoney, N., and Campbell, B. C. (2011). Antifungal activity of redox-active benzaldehydes that target cellular antioxidation. Ann. Clin. Microbiol. Antimicrob. 10:23. doi: 10.1186/1476-0711-10-23

Kim, J. H., Yu, J., Mahoney, N., Chan, K. L., Molyneux, R. J., Varga, J., et al. (2008). Elucidation of the functional genomics of antioxidant-based inhibition of aflatoxin biosynthesis. Int. J. Food Microbiol. 122, 49-60. doi: 10.1016/j.ijfoodmicro.2007.11.058

Kirkman, T. W. (2014). Statistics to Use. Available online at: http://www.physics. csbsju.edu/stats/ (Accessed: 8 January 2014).

Kojima, K., Takano, Y., Yoshimi, A., Tanaka, C., Kikuchi, T., and Okuno, T. (2004). Fungicide activity through activation of a fungal signalling pathway. Mol. Microbiol. 53, 1785-1796. doi: 10.1111/j.1365-2958.2004.04244.x

Lee, J., Kwon, E. S., Kim, D. W., Cha, J., and Roe, J. H. (2002). Regulation and the role of $\mathrm{Cu}, \mathrm{Zn}$-containing superoxide dismutase in cell cycle progression of Schizosaccharomyces pombe. Biochem. Biophys. Res. Commun. 297, 854-862. doi: 10.1016/S0006-291X(02)02290-8

Lussier, M., White, A. M., Sheraton, J., di Paolo, T., Treadwell, J., Southard, S. B., et al. (1997). Large scale identification of genes involved in cell surface biosynthesis and architecture in Saccharomyces cerevisiae. Genetics 147, 435-450.

Martin, H., Rodríguez-Pachón, J. M., Ruiz, C., Nombela, C., and Molina, M. (2000). Regulatory mechanisms for modulation of signaling through the cell integrity Slt2-mediated pathway in Saccharomyces cerevisiae. J. Biol. Chem. 275, 1511-1519. doi: 10.1074/jbc.275.2.1511

Miskei, M., Karányi, Z., and Pócsi, I. (2009). Annotation of stress-response proteins in the aspergilli. Fungal Genet. Biol. 46(Suppl. 1), S105-S120. doi: 10.1016/j.fgb.2008.07.013

Morano, K. A., Grant, C. M., and Moye-Rowley, W. S. (2012). The response to heat shock and oxidative stress in Saccharomyces cerevisiae. Genetics 190, 1157-1195. doi: 10.1534/genetics.111.128033

Niimi, K., Harding, D. R., Parshot, R., King, A., Lun, D. J., Decottignies, A., et al. (2004). Chemosensitization of fluconazole resistance in Saccharomyces cerevisiae and pathogenic fungi by a D-octapeptide derivative. Antimicrob. Agents Chemother. 48, 1256-1271. doi: 10.1128/AAC.48.4.1256-1271.2004

Ochiai, N., Fujimura, M., Oshima, M., Motoyama, T., Ichiishi, A., Yamada-Okabe, H., et al. (2002). Effects of iprodione and fludioxonil on glycerol synthesis and hyphal development in Candida albicans. Biosci. Biotechnol. Biochem. 66, 2209-2215. doi: 10.1271/bbb.66.2209

Odds, F. (2003). Synergy, antagonism, and what the chequerboard puts between them. J. Antimicrob. Chemother. 52:1. doi: 10.1093/jac/dkg301

Possiede, Y. M., Gabardo, J., Kava-Cordeiro, V., Galli-Terasawa, L. V., Azevedo, J. L., and Glienke, C. (2009). Fungicide resistance and genetic variability in plan pathogenic strains of Guignardia citricarpa. Braz. J. Microbiol. 40, 308-313. doi: 10.1590/S1517-83822009000200018

Reyes, G., Romans, A., Nguyen, C. K., and May, G. S. (2006). Novel mitogenactivated protein kinase MpkC of Aspergillus fumigatus is required for utilization of polyalcohol sugars. Eukaryot. Cell 5, 1934-1940. doi: 10.1128/EC.00178-06

Robles-Martinez, L., Guerra-Sanchez, M. G., Flores-Herrera, O., HernandezLauzardo, A. N., Velazquez-Del Valle, M. G., and Pardo, J. P. (2013). The mitochondrial respiratory chain of Rhizopus stolonifer (Ehrenb.:Fr.) Vuill. Arch. Microbiol. 195, 51-61. doi: 10.1007/s00203-012-0845-7
Rodriguez, S. B., and Mahoney, N. E. (1994). Inhibition of aflatoxin production by surfactants. Appl. Environ. Microbiol. 60, 106-110.

Roze, L. V., Hong, S. Y., and Linz, J. E. (2013). Aflatoxin biosynthesis: current frontiers. Annu. Rev. Food Sci. Technol. 4, 293-311. doi: 10.1146/annurev-food083012-123702

Ruy, F., Vercesi, A. E., and Kowaltowski, A. J. (2006). Inhibition of specific electron transport pathways leads to oxidative stress and decreased Candida albicans proliferation. J. Bioenerg. Biomembr. 38, 129-135. doi: 10.1007/s10863-006-9012-7

Saccharomyces Genome Database. Available online at: http://www.yeastgenome.org (Accessed: 10 January 2014).

Schmidt-Heydt, M., Stoll, D., and Geisen, R. (2013). Fungicides effectively used for growth inhibition of several fungi could induce mycotoxin biosynthesis in toxigenic species. Int. J. Food Microbiol. 166, 407-412. doi: 10.1016/j.ijfoodmicro.2013.07.019

Shirazi, F., and Kontoyiannis, D. P. (2013). Mitochondrial respiratory pathways inhibition in Rhizopus oryzae potentiates activity of posaconazole and itraconazole via apoptosis. PLoS ONE 8:e63393. doi: 10.1371/journal.pone. 0063393

Sierra-Campos, E., Valdez-Solana, M. A., Matuz-Mares, D., Velazquez, I., and Pardo, J. P. (2009). Induction of morphological changes in Ustilago maydis cells by octyl gallate. Microbiology 155, 604-611. doi: 10.1099/mic.0.020800-0

Sun, N., Fonzi, W., Chen, H., She, X., Zhang, L., Zhang, L., et al. (2013). Azole susceptibility and transcriptome profiling in Candida albicans mitochondrial electron transport chain complex I mutants. Antimicrob. Agents Chemother. 57, 532-542. doi: 10.1128/AAC.01520-12

Toone, W. M., and Jones, N. (1998). Stress-activated signalling pathways in yeast. Genes Cells 3, 485-498. doi: 10.1046/j.1365-2443.1998.00211.x

U.S. Food and Drug Administration (FDA). (2011). Everything Added to Food in the United States. Available online at: http://www.fda.gov/ Food/IngredientsPackagingLabeling/FoodAdditivesIngredients/ucm 115326.htm (Accessed: 8 January 2014).

Vincent, J. M. (1947). Distortion of fungal hyphae in the presence of certain inhibitors. Nature 159:850. doi: 10.1038/159850b0

Washburn, R. G., Gallin, J. I., and Bennett, J. E. (1987). Oxidative killing of Aspergillus fumigatus proceeds by parallel myeloperoxidase-dependent and independent pathways. Infect. Immun. 55, 2088-2092.

Wood, P. M., and Hollomon, D. W. (2003). A critical evaluation of the role of alternative oxidase in the performance of strobilurin and related fungicides acting at the Qo site of complex III. Pest Manag. Sci. 59, 499-511. doi: 10.1002/ ps. 655

Xue, T., Nguyen, C. K., Romans, A., and May, G. S. (2004). A mitogen-activated protein kinase that senses nitrogen regulates conidial germination and growth in Aspergillus fumigatus. Eukaryot. Cell 3, 557-560. doi: 10.1128/EC.3.2.557560.2004

Conflict of Interest Statement: The authors declare that the research was conducted in the absence of any commercial or financial relationships that could be construed as a potential conflict of interest.

Received: 25 January 2014; paper pending published: 06 February 2014; accepted: 18 February 2014; published online: 07 March 2014.

Citation: Kim JH, Mahoney N, Chan KL, Campbell BC, Haff RP and Stanker LH (2014) Use of benzo analogs to enhance antimycotic activity of kresoxim methyl for control of aflatoxigenic fungal pathogens. Front. Microbiol. 5:87. doi: 10.3389/fmicb. 2014.00087

This article was submitted to Food Microbiology, a section of the journal Frontiers in Microbiology.

Copyright (c) 2014 Kim, Mahoney, Chan, Campbell, Haff and Stanker. This is an open-access article distributed under the terms of the Creative Commons Attribution License (CC BY). The use, distribution or reproduction in other forums is permitted, provided the original author(s) or licensor are credited and that the original publication in this journal is cited, in accordance with accepted academic practice. No use, distribution or reproduction is permitted which does not comply with these terms. 